\title{
The Clostridium difficile problem: A South African tertiary institution's prospective perspective
}

\author{
N Rajabally, M Pentecost, G Pretorius, A Whitelaw, M Mendelson, G Watermeyer \\ Division of Gastroenterology, Department of Medicine, Groote Schuur Hospital and University of Cape Town \\ N Rajabally, MB BCh, FCP (SA), Cert Gastroenterology \\ G Watermeyer, MB ChB, FCP (SA), Cert Gastroenterology \\ Division of Internal Medicine, Department of Medicine, Groote Schuur Hospital and University of Cape Town \\ M Pentecost, MB ChB
}

Division of Medical Microbiology, Pathcare Laboratories, Cape Town

O Pretorius, $\mathrm{PhD}$

National Health Laboratory Service, Groote Schuur Hospital and Division of Medical Microbiology, University of Cape Town A Whitelaw, MB BCh, MSc, FCPath (Micro)

Division of Infectious Diseases and HIV Medicine, Department of Medicine, Groote Schuur Hospital and University of Cape Town M Mendelson, BSc, PhD, MB BS, FRCP (UK), DTM\&H

Corresponding author: N Rajabally (naayil@gmail.com)

\begin{abstract}
Background and objectives. The aim of this study is to report the incidence of Clostridium difficile-associated disease (CDAD) in a tertiarycare hospital in South Africa and to identify risk factors, assess patient outcomes and determine the impact of the hypervirulent strain of the organism referred to as North American pulsed-field type 1 (NAP1).

Methods. Adults who presented with diarrhoea over a period of 15 months were prospectively evaluated for CDAD using stool toxin enzyme immunoassay (EIA). Positive specimens were evaluated by PCR. Patient demographics, laboratory parameters and outcomes were analysed.

Results. CDAD was diagnosed in 59 (9.2\%) of 643 patients (median age 39 years, IQR 30 - 55). Thirty-four (58\%) were female. Recent antibiotic exposure was reported in 39 (66\%), 27 (46\%) had been hospitalised within 3 months, and 14 (24\%) had concomitant inflammatory bowel disease (IBD). Nineteen (32\%) had community-acquired CDAD (CA-CDAD). The annual incidence of hospital-acquired CDAD (HA-CDAD) was 8.7 cases/10 000 hospitalisations. Two cases of the hypervirulent strain NAP1 were identified. Seven (12\%) patients underwent colectomy (OR 6.83; 95\% CI 2.41 - 19.3). On logistic regression, only antibiotic exposure independently predicted for CDAD (OR 2.9; 95\% CI 1.6 - 5.1). Three (16\%) cases of CA-CDAD reported antibiotic exposure (v. 90\% of HA-CDAD, $p<0.0001)$. Twelve (86\%) patients had concomitant IBD $(p<0.0001 \mathrm{v}$. HA-CDAD). CA-CDAD was significantly associated with antibiotic exposure (OR $0.04,95 \%$ CI $0.01-0.24)$ and IBD (OR 9.6, 95\% CI 1.15 - 79.8).

Conclusion. The incidence of HA-CDAD in the South African setting is far lower than that reported in the West. While antibiotic use was a major risk factor for HA-CDAD, CA-CDAD was not associated with antibiotic therapy. Concurrent IBD was a predictor of CA-CDAD.

S Afr Med J 2013;103(3):168-172. DOI:10.7196/SAMJ.6012
\end{abstract}

Clostridium difficile is a Gram-positive, spore-forming anaerobic bacillus that causes disease by producing cytotoxins. The clinical outcome depends on host immunity and the virulence of the toxin-producing strain. ${ }^{[1]}$ C. difficile causes disease that ranges in severity from asymptomatic colonisation to severe diarrhoea, pseudomembranous colitis (PMC), toxic megacolon, colonic perforation and death. ${ }^{[2]}$

Over the last decade, there has been a dramatic increase in the incidence and severity of $C$. difficile-associated diarrhoea (CDAD), predominantly affecting Western countries. The striking change in epidemiology, clinical severity and case-fatality ratio is attributable in part to the emergence of a strain, identified as the North American pulsed-field type 1 (NAP1), referred to more commonly in Europe as Type 027. This hypervirulent strain produces increased amounts of toxins and is resistant to the fluoroquinolones. ${ }^{[3]}$

Data regarding the burden of CDAD in southern Africa are limited. The magnitude of $C$. difficile infection in South African hospitals is not known and it is also unclear what proportion of CDAD is community-acquired (CA-CDAD). Therefore, the aims of this study were to investigate the incidence of CDAD in a tertiary referral hospital, to evaluate associated risk factors and effect on patient morbidity and mortality, to report on the presence of NAP1 and to determine the percentage of CA-CDAD.

\section{Methods}

The study was conducted at Groote Schuur Hospital (GSH), a 943-bed tertiary referral hospital in Cape Town. All adult patients 
admitted with diarrhoea, or who developed diarrhoea following admission for an unrelated condition, were evaluated prospectively over 15 months. Stool was tested for Toxin A using standard enzyme immunoassay (EIA). DNA was extracted from toxin-positive stool and subsequently subjected to real-time PCR. Demonstration of an 18-base pair deletion of the tcd $\mathrm{C}$ gene, after amplification, indicated the presence of NAP1 strain. ${ }^{[4]}$

$\mathrm{CDAD}$ was diagnosed in cases with diarrhoea that were confirmed Toxin A positive. Patients with diarrhoea and demonstrable pseudomembranous colitis at endoscopy or at histopathology were also diagnosed as having CDAD. Persons under 18 years of age, and adults who provided formed stool samples to the laboratory, were excluded from the study.

The Centres for Disease Control (CDC)-recommended definitions for diarrhoea were adopted. ${ }^{[5]}$ Diarrhoea was considered as hospitalacquired if it had started more than 48 hours after admission, or if patients had resided in a long-term care facility, or if patients had been discharged from hospital or long-term care facility 14 days prior to presentation. CDAD was defined as diarrhoea that started before hospital admission or within 48 hours following admission.

The study was approved by the Ethics Committee of the University of Cape Town.

\section{Statistical analysis}

Statistical analysis was performed using Stata Statistical Software: Release 11 (StataCorp, College Station, USA). Continuous variables were expressed as medians and interquartile ranges (all variables in the final analysis had a non-Gaussian distribution). The MannWhitney test was used to assess continuous variables, while the chi-square or Fisher's exact test was used for categorical variables. Univariate analysis was performed initially for each variable. Variables differing between groups with a significance level of $p<0.1$ and other possible confounders identified a priori, were then entered into a series of multivariate logistic regression models. Age was treated as a categorical variable ( $<30$ years, $30-49$ years, 50 -
64 years, $\geq 65$ years). Models were built sequentially, starting with the variable most strongly associated with the outcome. A $p$-value $\leq 0.05$ was considered significant in the multivariate model. Some baseline variables that were significant on univariate analysis were omitted from the final models owing to collinearity. Different models were compared by using the likelihood ratio test, with significance determined at a $p$-value of 0.05 .

\section{Results}

A total of 651 patients were enrolled. Eight were excluded owing to incomplete data, leaving 643 patients in the final analysis. Baseline characteristics are presented in Table 1. Fifty-nine (9.2\%) individuals were diagnosed with CDAD, of whom $34(58 \%)$ were female. The diagnosis was made by toxin detection in $51(86.4 \%)$ patients. An additional $6(10.2 \%)$ had features of pseudomembranous colitis at endoscopy and $2(3.4 \%)$ at histopathology.

Among the CDAD cases, 39 (66\%) had had recent antibiotic exposure (within 28 days of diagnosis) and $27(46 \%)$ had been hospitalised within the previous 3 months; both variables were significantly associated with $C$. difficile infection on univariate analysis. Sixty-four per cent of patients with CDAD had been exposed to penicillin-based antibiotics - $26 \%$ to quinolones, $23 \%$ to carbapenems, $13 \%$ to cephalosporins and $3 \%$ to clindamycin. Although not statistically significant, there was a trend for increased use of proton pump inhibitors (PPIs) in subjects with CDAD compared with those without ( $49 \%$ v. $39 \%, p=0.089$ ). No baseline laboratory marker was significantly associated with CDAD (Table 2). On logistic regression analysis (Table 3), only recent antibiotic exposure was identified as an independent predictor for CDAD (odds ratio (OR) 2.9; 95\% CI 1.6 - 5.1).

HA-CDAD was diagnosed in 40 subjects (67.8\%), $90 \%$ of whom had had recent exposure to antibiotics, giving an annual incidence of HA-CDAD of 8.7 cases per 10000 hospitalisations. Of the 19 (32.2\%) patients with CA-CDAD, only $3(16 \%)$ reported recent exposure to antibiotics, compared with $90 \%$ with HA-CDAD $(p<0.0001)$.

Table 1. Baseline clinical characteristics

\begin{tabular}{llll}
\hline Variable & C. diff +ve $(\boldsymbol{n}=\mathbf{5 9})$ & C. diff-ve $(\boldsymbol{n}=\mathbf{5 8 4})$ & $\boldsymbol{p}$-value \\
\hline Age (years), median (IQR) & $39(30-55)$ & $42(32-56.5)$ & 0.200 \\
Gender (female), $n$ (\%) & $34(58)$ & $353(61)$ & 0.700 \\
Ethnicity, $n$ (\%) & & & 0.600 \\
$\quad$ Black & $16(27)$ & $179(31)$ & \\
White & $5(9)$ & $75(13)$ & \\
Coloured & $36(61)$ & $317(54)$ & \\
Asian & $2(3)$ & $13(2)$ & 0.200 \\
Co-morbid condition, $n$ (\%) & & & \\
$\quad$ None & $4(7)$ & $32(5)$ & \\
IBD & $14(24)$ & $171(29)$ & \\
HIV & $16(27)$ & $121(21)$ & \\
Diabetes & $2(3)$ & $31(5)$ & \\
Malignancy & $9(15)$ & $44(8)$ & 0.014 \\
Other & $14(24)$ & $185(32)$ & $<0.0001$ \\
Prior hospitalisation (within 90 days), $n$ (\%) & $27(46)$ & $176(30)$ & 0.089 \\
Recent antibiotic use (within 28 days), $n(\%)$ & $39(66)$ & $229(39)$ & $221(38)$ \\
Concurrent PPI use, $n$ (\%) & $29(49)$ &
\end{tabular}




\section{RESEARCH}

\begin{tabular}{llll} 
Table 2. Baseline laboratory parameters & & & \\
\hline Variable & C. diff +ve & C. diff -ve & p-value \\
\hline Haemoglobin $(\mathrm{g} / \mathrm{dl})$, median $(\mathrm{IQR})$ & $9.7(8.3-12.3)$ & $10.6(8.6-12.6)$ & 0.1 \\
White cell count $\left(10^{9} / \mathrm{l}\right)$, median $(\mathrm{IQR})$ & $8.5(5.5-11.5)$ & $9.5(6.7-14.1)$ & 0.06 \\
Albumin $(\mathrm{g} / \mathrm{l})$, median $(\mathrm{IQR})$ & $31(22-40)$ & $31(24-39)$ & 0.6 \\
Creatinine $(\mu \mathrm{mol} / \mathrm{l})$, median $(\mathrm{IQR})$ & $72.5(50-116.5)$ & $79(58-127)$ & 0.3 \\
C-reactive protein $(\mathrm{mg} / \mathrm{l})$, median $(\mathrm{IQR})$ & $45.8(8.9-157.4)$ & $32.6(9.1-112.1)$ & 0.7
\end{tabular}

\begin{tabular}{|c|c|c|c|c|}
\hline Variable & $N$ & \% with C. Diff & Crude OR (95\% CI) & Adjusted OR (95\% CI) \\
\hline \multicolumn{5}{|c|}{ Age (years) } \\
\hline$<30$ & 121 & 11.6 & 1.0 referent & 1.0 referent \\
\hline $30-49$ & 301 & 9.0 & $0.8(0.4-1.5)$ & $0.8(0.4-1.6)$ \\
\hline $50-64$ & 127 & 8.7 & $0.7(0.3-1.7)$ & $0.8(0.3-1.7)$ \\
\hline$\geq 65$ & 94 & 7.5 & $0.6(0.2-1.6)$ & $0.7(0.3-1.8)$ \\
\hline \multicolumn{5}{|l|}{ Gender } \\
\hline Male & 256 & 9.8 & 1.0 referent & 1.0 referent \\
\hline Female & 387 & 8.8 & $0.9(0.5-1.5)$ & $0.9(0.5-1.6)$ \\
\hline \multicolumn{5}{|c|}{ Recent antibiotics } \\
\hline No & 373 & 5.4 & 1.0 referent & 1.0 referent \\
\hline Yes & 268 & 14.6 & $3.0(1.7-5.3)$ & $2.9(1.6-5.1)$ \\
\hline \multicolumn{5}{|c|}{ Previous hospitalisations } \\
\hline No & 440 & 7.3 & 1.0 referent & 1.0 referent \\
\hline Yes & 203 & 13.3 & $1.96(1.1-3.4)$ & $1.8(1-3.1)$ \\
\hline
\end{tabular}

\begin{tabular}{|c|c|c|c|}
\hline & HA-CDAD $(N=40)$ & CA-CDAD $(N=19)$ & $p$-value \\
\hline Age (years), median (IQR) & $36.5(29-55)$ & $41(31-55)$ & 0.710 \\
\hline Gender (female), $n(\%)$ & $20(50)$ & $5(26)$ & 0.085 \\
\hline Race, $n(\%)$ & & & 0.180 \\
\hline White & $4(10)$ & $1(5)$ & \\
\hline Black & $14(35)$ & $2(11)$ & \\
\hline Coloured & $21(53)$ & $15(79)$ & \\
\hline Asian & $1(2)$ & $1(5)$ & \\
\hline Previous admission, $n$ (\%) & $19(48)$ & $8(42)$ & 0.700 \\
\hline Recent antibiotic use, $n$ (\%) & $36(90)$ & $3(16)$ & $<0.0001$ \\
\hline PPI use, $n(\%)$ & $21(53)$ & $8(42)$ & 0.4600 \\
\hline Co-morbid conditions, $n$ (\%) & & & 0.060 \\
\hline None & $1(2)$ & $3(16)$ & \\
\hline Diabetes & $2(5)$ & $0(0)$ & \\
\hline HIV & $14(35)$ & $2(11)$ & \\
\hline Malignancy & $8(20)$ & $1(5)$ & \\
\hline IBD & $2(5)$ & $12(63)$ & $<0.0001$ \\
\hline Other & $13(33)$ & $1(5)$ & \\
\hline Any co-morbid condition & $39(98)$ & $16(84)$ & \\
\hline Type of IBD, $n(\%)$ & & & 0.830 \\
\hline Ulcerative colitis & $1(50)$ & $5(42)$ & \\
\hline Crohn's disease & $1(50)$ & $7(58)$ & \\
\hline
\end{tabular}

Fourteen (24\%) patients with CDAD had concomitant IBD, 12 (86\%) of whom acquired the disease in the community $(p<0.0001$ v. HA-CDAD). Table 4 compares the characteristics of HA-CDAD with CA-CDAD. Subjects with HA-CDAD had a significantly lower median baseline haemoglobin ( $8 \mathrm{~g} / \mathrm{dl} \mathrm{v.} 12 \mathrm{~g} / \mathrm{dl}, p<0.0001)$ and serum albumin (24 g/l v. $41.5 \mathrm{~g} / \mathrm{l}, p<0.0001)$ as well as significantly higher 
C-reactive protein levels $(83.5 \mathrm{mg} / \mathrm{l} \mathrm{v.} 4 \mathrm{mg} / \mathrm{l}, p=0.002)$ than subjects with CA-CDAD. There was no difference in baseline white blood cell counts or serum creatinine. On regression analysis, only recent antibiotic exposure (OR 0.04, 95\% CI 0.01 - 0.24) and the presence of co-morbid IBD (OR 9.6, 95\% CI 1.15 - 79.8) were predictors of CA- CDAD.

Seven (12\%) patients with CDAD underwent colectomy (Table 5 ), which on regression analysis was significantly associated with C. difficile infection (OR 6.83; 95\% CI 2.41 - 19.3). However, no difference was observed in duration of hospital stay or the need for ICU care between subjects with and without $C$. difficile infection. There was no significant difference in mortality rates; the 30-day mortality rate for subjects with CDAD was $66.7 \%$. Two (3.4\%) cases of HA-CDAD owing to NAP1 were identified, both of which proved fatal.

Forty-four (74.6\%) patients with CDAD were treated with metronidazole, 3 (5.2\%) with oral vancomycin and 8 (13.4\%) with a combination of oral vancomycin and metronidazole. Four (6.8\%) patients received no antibiotics directed at $C$. difficile, 2 of whom underwent colectomy. Three (5.1\%) patients had recurrent disease, all being successfully treated with antibiotics.

\section{Discussion}

Over the last decade, there has been concern about the rising incidence, disease severity and mortality associated with CDAD. The number of reported cases in the UK rose from 7470 in 1994 to 43682 in 2004 Stoke Mandeville Hospital reported 2 outbreaks between 2003 and 2005 that resulted in 38 deaths ${ }^{[6]}$ Similarly in Quebec, Canada, the overall incidence of CDAD quadrupled in 2003, with a reported 30-day mortality of $6.9 \%$ in one study. ${ }^{[7]}$ This markedly increased incidence has been attributed to the NAP1 strain of $C$. difficile that carries a mutation in the tcd $\mathrm{C}$ gene, a negative regulator of toxin production, as a result of which the NAP1 strain produces more than 10 times the quantity of toxin than conventional strains. ${ }^{[3]}$ NAP1 also produces an additional toxin, the so-called Binary toxin, which may act synergistically with Toxins $\mathrm{A}$ and $\mathrm{B}$ in causing disease. ${ }^{[8,9]}$

In southern Africa, data regarding $C$. difficile are scarce. Samie et al. undertook PCR detection of $C$. difficile in adults attending an outpatient department and in school-going children in the Vhembe District, South Africa. ${ }^{[10]}$ They found a prevalence of $14 \%$ of C. difficile among study participants. However, the incidence of CDAD in SA hospitals remains undetermined. In 2008, Lekalakala et al. reported on an increase in CDAD at their tertiary hospital in Pretoria and highlighted the importance of preventive measures involving close co-ordination between the laboratory and infection control teams. ${ }^{[11]}$ Whether this apparent increase was caused by the NAP1 strain was not evaluated.

Overall, the annual incidence of HA-CDAD was 0.87 cases per 1000 hospitalisations, which is far lower than Western experience, where CDAD incidence rates of 7.4 cases per 1000 admissions have been reported. ${ }^{[12]} \mathrm{A}$ possible explanation for this lower burden of disease may be the generally younger SA hospital patient population. The median age in our study was 41 years. However, when comparing patients 65 years and older with those 30 years and younger, an increased risk of developing CDAD was not observed (OR 0.7, $95 \%$ CI 0.3 - 1.8). Another possible explanation may be the strict antimicrobial stewardship programme adopted at GSH, given that limiting the use of antibiotics has been shown to decrease the occurrence of CDAD. ${ }^{[1,14]}$ The possibility remains that all cases of C. difficile might not have been identified, and the incidence of CDAD underestimated. Stool EIA for Toxin A lacks sensitivity and may miss cases producing toxin $B$ only ${ }^{[4,9]}$ Another study limitation is that our hospital is a large, urban, tertiary-care teaching facility that may not be representative of other institutions.

Several risk factors render patients vulnerable to CDAD. The only independent variable in this study that was found to be strongly associated with CDAD, was recent exposure to antibiotics. ${ }^{[15-17]}$ The hospital milieu serves as an important reservoir for resistant spores that may be passed on to individuals who then develop disease some time after exposure. Although univariate analysis suggested an increased risk of CDAD in subjects previously admitted to a healthcare facility within 90 days $(p=0.014$ ), significance was lost on multivariate analysis. SA is a high HIV-prevalent country, yet CDAD was not associated in this study with HIV infection. The relationship between CDAD and PPIs remains controversial, ${ }^{[18]}$ but their use was shown not to significantly increase the risk for CDAD in this study.

While an elevated white cell count, hypo-albuminaemia, impaired renal function and raised inflammatory markers have been associated with severe CDAD, we did not find these parameters to be of significance. However, it bears noting that our control group also had serious illnesses with abnormal inflammatory and other markers. Similarly, the length of hospital stay, need for ICU admission, and mortality as outcome of disease did not reach significance. It is important to note that 1 in 5 patients who developed CDAD during the course of their illness eventually died. Subjects with CDAD had an almost seven-fold increase in colectomy.

Several reports have highlighted an increased incidence of CDAD in patients with IBD. ${ }^{[19.23]}$ As in our study, it has been noted that IBD patients are particularly prone to $\mathrm{CA}-\mathrm{CDAD}$, even during remission and often without prior exposure to antibiotics. ${ }^{[24]}$

In conclusion: This is the first study, to our knowledge, that prospectively documents the impact of CDAD in a southern African hospital. The burden of disease is significantly lower than in the West, perhaps because the NAP1 strain has fortunately not reached the levels reported in countries recently experiencing severe outbreaks.

Acknowledgements. The authors thank Professor Sandie Thomson for reviewing the manuscript, Henri Carrara and Motasim Badri for statistical input, and the Gastroenterology Foundation, Discovery Foundation, and Medical Research Council of South Africa for funding support.

Table 5. Length of hospital stay, need for ICU care and outcome of cases with CDAD and controls

\begin{tabular}{llll}
\hline Variable & C. diff +ve & C. diff -ve & $p$-value \\
\hline Duration of hospital stay (days), median (IQR) & $19(8-29)$ & $17(7-33)$ & 0.700 \\
ICU admission, $n$ (\%) & $17(37)$ & $116(28)$ & 0.200 \\
Colectomy, $n(\%)$ & $7(12)$ & $13(2)$ & 0.001 \\
Death, $n(\%)$ & $12(20)$ & $92(16)$ & 0.400
\end{tabular}




\section{RESEARCH}

\section{References}

1. Leffler DA, Lamont JT. Treatment of Clostridium difficile-associated disease. Gastroenterolog/ 2009;136:1899-1912. [http://dx.doi.org/10.1053/.gastro.2008.12.070]

2. Gerding DN, Johnson S, Peterson LR, Mulligan MB, Silva J Jr. Clostridium difficile-associated diarrhoe and colitis. Infect Control Hosp Epidemiol 1995;16:459-477. [http://dx.doi.org/10:1086/502601]

3. Kelly PC, LaMont JT. Clostridium difficile - More difficult than ever. N Engl J Med 2008;359:1932-40. [http://dx.doi.org/10.1056/NEJMra0707500]

4. Sloan LM, Duresko BJ, Gustafson DR, Rosenblatt JE. Comparison of real-time PCR for detection of the tcdC gene with four toxin immunoassays and culture in diagnosis of Clostridium difficile infection. I Clin Microbiol 2008;46:1996-2001. [http://dx.doi.org/10.1128/JCM.00032-08]

5. McDonald LC, Coignard B, Dubberke E, et al. Recommendations for surveillance of Clostridiun difficile-associated disease. Infect Control Hosp Epidemiol 2007:28(2):140-145. [http://dx.do org/10.1086/511798]

6. Commission for Healthcare Audit and Inspection - Investigation into outbreaks of Clostridium difficile at Stoke Mandeville Hospital, Buckinghamshire Hospitals NHS Trust, 2006. http://www buckshealthcare.nhs.uk.

7. Pépin I Valiquette L, Alary M, et al. Clostridium difficile-associated diarrhea in a region of Quebec from 1991 to 2003: a changing pattern of disease severity CMAJ 2004:171(5):466-472. [http://dx do org/10.1503/cmaj.1041104

8. O'Connor IR, Johnson S, Gerding DN. Clostridium difficile infection caused by the Epidemic

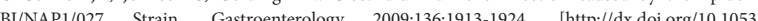
gastro.2009.02.073

9. Cohen SH, Gerding ND, Johnson S, et al. Clinical Practice Guidelines for Clostridium difficie

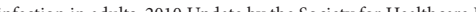
Co 455. [http://dx.doi.org/10.1086/651706]

10. Samie A, Obi CL, Franasiak J, et al. PCR detection of Clostridium difficile triose phosphate isomerase (ti), Ton A (c (tpi), South Africa. Am J Trop Med Hyg 2008; $78(4): 577-585$.

11. Lekalakala MR,Lewis E, Hoosen AA. Clostridium difficile infections in a tertiary hospital: value of surveillance. J Hosp Infect 2010;75(4): 328-329. [http://dx.doi.org/10.1016/j.jhin.2010.03.016]

12. Sohn S, Climo MW, Diekema D, et al. Varying rates of Clostridium difficile-associated diarrhea prevention epicenter hospitals. Infect Control Hosp Epidemiol 2005;26(8):676-679. [http://dx.doi. org/10.1086/502601]
13. Climo MW, Israel DS, Wong ES, Williams D, Coudron P, Markowitz SM. Hospital-wide restriction of clindamycin: effect on the incidence of Clostridium difficile-associated diarrea and cost. Ann Intern Med 1998;128:989-995.

14. Valiquette L, Cossette B, Garant MP, Diab H, Pepin J. Impact of a reduction in the use of high-risk antibiotics on the course of an epidemic of Clostridium difficile-associated disease caused by the hypervirulen NAP1/027 strain. Clin Infect Dis 2007;45(Suppl 2):S112-S121. [http://dx.doi.org/10.1086/519258]

5. Thibault A, Miller MA, Gaese C. Risk factors for the development of Clostridium difficile-associated diarrhea during a hospital outbreak. Infect Control Hosp Epidemiol 1991;12:345-348. [http://dx.doi. org $/ 10.2307 / 30145209$

16. Chang HT, Krezolek D, Johnson S, Parada JP, Evans CT, Gerding DN. Onset of symptoms and time to diagnosis of Clostridium difficile-associated disease following discharge from an acute care hospital. Infect Control Hosp Epidemiol 2007;28:926-931. [http://dx.doi.org/10.1086/519178]

17. Bignardi GE. Risk factors for Clostridium difficile infection. J Hosp Infect 1998;40:1-15

18. Thomson AB, Sauve MD, Kassam N, Kamitakahara H. Safety of the long-tem use of proton pum inhibitors. World J Gastroenterol 2010; 16(19):2323-2330. [http://dx.doi.org/10.3748/wg.v16.i19.2323]

19. Rodemann JF, Dubberke ER, Reske KA, Seo da H, Stone CD. Incidence of Clostridium difficile infection in inflammatory bowel disease. Clin Gastroenterol Hepatol 2007;5:339-344. [http://dx.doi. org/10.1016/j.cgh.2006.12.027]

20. Issa M, Vijayapal A, Graham MB, et al. Impact of Clostridium difficile on inflammatory bowel disease. Clin Gastroenterol Hepatol 2007;5:345-351. [http://dx.doi.org/10.1016/j.cgh.2006.12.028]

1. Ananthakrishnan AN, McGinley EL, Binion DG. Excess hospitalisation burden associated with Clostridium difficile in patients with inflammatory bowel disease. Gut 2008;57:205-210. [http://dx.do org/10.1136/gut.2007.128231]

22. Nguyen GC, Kaplan GG, Harris ML, Brant SR. A national survey of the prevalence and impact o Clostridium difficile infection among hospitalized inflammatory bowel disease patients. Am Gastroenterol 2008;103:1443-1450. [http://dx.doi.org/10.1111/j.1572-0241.2007.01780.x]

23. Bossuyt P, Verhaegen J, Van Assche G, Rutgeerts P, Vermeire S. Increasing incidence of Clostridium difficile-associated diarrhea in inflammatory bowel disease. J Crohn's Colitis 2009;3:4-7. [http://dx.do org/10.1016/j.crohns.2008.09.003

24. Navaneethan U, Venkatesh PG, Shen B. Clostridium difficile infection and inflammatory bowe disease: Understanding the evolving relationship. World J Gastroenterol 2010;16:4892-4904. [http:// dx.doi.org/10.3748/wig.v16.i39.4892]

Accepted 23 October 2012 